\title{
Montelukast attenuates the airway response to hypertonic saline in moderate-to-severe COPD
}

\author{
I.E. Zühlke, F. Kanniess, K. Richter, D. Nielsen-Gode, S. Böhme, R.A. Jörres, H. Magnussen
}

\begin{abstract}
Montelukast attenuates the airway response to hypertonic saline in moderate-to-severe COPD. I.E. Zühlke, F. Kanniess, K. Richter, D. Nielsen-Gode, S. Böhme, R. A. Jörres, H. Magnussen. (C) ERS Journals Ltd 2003.

ABSTRACT: This study assessed the effect of the leukotriene receptor antagonist montelukast on hypertonic saline-induced airway obstruction.

A total of 29 patients with chronic obstructive pulmonary disease (forced expiratory volume in one second (FEV1), $42 \pm 4 \%$ predicted) received either $10 \mathrm{mg}$ montelukast and $3 \mathrm{~h}$ later placebo via metered-dose inhaler (MDI) (M), or placebo and 3h later $200 \mu \mathrm{g}$ salbutamol (S), or two doses of placebo (P), in a randomised order. Patients inhaled salbutamol $1 \mathrm{~h}$ after MDI and the challenge was performed 15 min later (3\% saline, $5 \mathrm{~min})$. Data are given as per cent changes versus baseline.

Compared to P, S caused significant bronchodilation in FEV1 $(7.3 \%)$ and forced inspiratory volume in one second (FIV1) $(4.5 \%)$, and $M$ in FIV1 $(1.5 \%)$. The salineinduced fall in FEV1 was lower after $M(-5.8 \%)$, compared with $S(-10.3 \%)$ and $P$ $(-13.1 \%)$. FEV1 $(11.3 \%)$ and FIV1 $(7.6 \%)$ was improved over baseline after recovery by $M$ but not $P$ and $S$. Recovery times regarding FEV1 (8.5 min) and FIV1 (15.2 min) were shortest after $M$, respective values for $S$ being 16.8 and $20.4 \mathrm{~min}$, and for $P \mathbf{1 5 . 9}$ and $21.2 \mathrm{~min}$. Effects were strongest in patients with low baseline FEV1 and/or inhaled corticosteroids.

Data from this study indicate beneficial effects of montelukast on hypertonic salineinduced airway responses in patients with chronic obstructive pulmonary disease, particularly those with severe disease. The major effect was an accelerated recovery leading to values above baseline.

Eur Respir J 2003; 22: 926-930.
\end{abstract}

Pulmonary Research Institute, Hospital Großhansdorf, Center for Pneumology and Thoracic Surgery, Großhansdorf, Germany.

Correspondence: I. Zühlke, Pulmonary Research Institute, Hospital Großhansdorf, Center for Pneumology and Thoracic Surgery, Wöhrendamm 80, D-22927 Großhansdorf, Germany.

Fax: 494102692295

E-mail: i.zuehlke@pulmoresearch.de

Keywords: Airway obstruction

airway protection

antileukotrienes

corticosteroids

recovery time

salbutamol

Received: April 252003

Accepted after revision: July 92003

This study was supported by an educational grant from Merck Sharpe Dohme $\mathrm{GmbH}$, Haar, Munich.
Inhalation of hypertonic saline has long been introduced as a method of bronchial challenge in patients with asthma [1]. Owing to the widespread use of sputum induction, such inhalation procedures are also used in patients with chronic obstructive pulmonary disease (COPD). Available data indicate that, unexpectedly, these patients often experience significant airway obstruction after hypertonic saline inhalation [2-5]. Whether this experimental response has a clinical correlate is currently unknown.

The adverse response occurs despite prior administration of a $\beta_{2}$-agonist, which is strongly recommended for sputum induction [6]. Besides the inability of a $\beta_{2}$-agonist to afford complete protection, little is known about the protective measures against the effects of hypertonic saline in COPD. In contrast, studies in patients with asthma have revealed significant protection by different types of drugs, such as antihistamines and nedocromil, suggesting mast cell activation and neural pathways as potential mechanisms [7-9].

Mast cell activation could also play a role in COPD, as indicated by the increase in histamine and tryptase levels in sputum immediately after provocation [5]; there was also a tendency towards increased levels of cysteinyl leukotrienes. Taking into account that leukotriene release might require more time than that of histamine and that leukotriene measurements in sputum are difficult [10], the current study aimed to reveal by direct intervention whether cysteinyl leukotrienes are involved in the hypertonic saline response in COPD.
To test this hypothesis, a double-blind, cross-over study in patients with moderate-to-severe COPD was performed using the specific cysteinyl leukotriene receptor antagonist montelukast in comparison with salbutamol and placebo. The time course of the obstructive airway response to hypertonic saline inhalation was chosen as the outcome measure.

\section{Patients and methods}

\section{Patients}

A total of 30 outpatients with moderate-to-severe stable COPD [11] and forced expiratory volume in one second $($ FEV 1$) \leqslant 60 \%$ pred were included and data from 29 patients were evaluated (table 1), since one patient was not willing to accept the saline response. None of the patients showed a history of asthma. All patients gave their written informed consent after approval of the study by the local Ethics Committee.

\section{Study protocol}

The protocol comprised one screening and three study days, separated by $\geqslant 3$ and $\leqslant 10$ days. Inhaled short- or longacting bronchodilators were withheld for $\geqslant 6$ or $\geqslant 12 \mathrm{~h}$, respectively, before measurements; all other medication was 
Table 1.-Patients' characteristics

\begin{tabular}{lc}
\hline Sex F/M & \\
Age yrs & $7 / 22$ \\
Height cm & $64 \pm 5$ \\
BMI kg $\cdot \mathrm{m}^{-2}$ & $174 \pm 9$ \\
Smoker ex/current & $23.5 \pm 5.2$ \\
Pack yrs & $15 / 14$ \\
IVC L & $68 \pm 28$ \\
FEV1 L & $3.48 \pm 0.78$ \\
FEV1 \% pred & $1.27 \pm 0.33$ \\
FIV1 L & $42 \pm 4$ \\
PEF L $\cdot \mathrm{s}^{-1}$ & $3.27 \pm 0.72$ \\
PIF L $\cdot \mathrm{s}^{-1}$ & $3.95 \pm 1.14$ \\
sRawex $\mathrm{cmH}_{2} \mathrm{O} \cdot \mathrm{s}^{-1}$ & $4.93 \pm 1.61$ \\
sRawin $\mathrm{cmH} \mathrm{O}_{2} \mathrm{O} \cdot \mathrm{s}^{-1}$ & $4.61 \pm 2.48$ \\
ITGV \% pred & $2.44 \pm 1.02$ \\
RV L & $154 \pm 25$ \\
TLC L & $4.13 \pm 1.03$ \\
TL,CO $\%$ pred & $7.46 \pm 1.42$ \\
\hline
\end{tabular}

Data are presented as mean \pm SD unless otherwise stated. F: female; M: male; BMI: body mass index; IVC: inspired vital capacity; FEV1: forced expiratory volume in one second; $\%$ pred: $\%$ predicted; FIV1: forced inspiratory volume in one second; PEF: peak expiratory flow; PIF: peak inspiratory flow; sRawex: specific airway resistance during expiration; sRawin: specific airway resistance during inspiration; ITGV: intrathoracic gas volume; RV: residual volume; TLC: total lung capacity; TL,CO: transfer factor of the lung for carbon monoxide.

left unchanged. The screening day served to assess medical history, clinical state and lung function including carbon monoxide transfer factor.

Afterwards, three combinations of oral and inhaled medication were tested in a randomised, double-blind, cross-over design; montelukast plus placebo metered-dose inhaler (MDI), oral placebo plus salbutamol MDI, and oral placebo plus placebo MDI. On each study day patients underwent baseline lung function testing and then received either $10 \mathrm{mg}$ montelukast or placebo. Patients inhaled either $200 \mu \mathrm{g}$ salbutamol or placebo through an MDI $3 \mathrm{~h}$ later. Lung function was reassessed $1 \mathrm{~h}$ later $(4 \mathrm{~h}$ after start) to quantify bronchodilation. Under all treatments patients then inhaled $200 \mu \mathrm{g}$ salbutamol and $15 \mathrm{~min}$ later, after additional lung function measurement, 3\% saline from an ultrasonic nebuliser (NE-U12; Omron, Tokyo, Japan [12]) for $5 \mathrm{~min}$; the additional lung function test was omitted in nine patients to reduce the number of forced manoeuvres, as the morning value was considered as a reference for comparison. Lung function was monitored by spirometry immediately after saline inhalation, and $5,15,25,35$, and $45 \mathrm{~min}$ afterwards to monitor recovery. Patients were not requested to produce sputum, as the hypertonic saline was only used for inhalation challenge.

\section{Lung function measurements}

A body plethysmograph (Masterlab, Jaeger, Würzburg, Germany) was used to assess specific airway resistance during in- and expiration, intrathoracic gas volume, residual volume, total lung capacity and inspired vital capacity, as well as FEV1 and forced inspiratory volume in one second (FIV1) from forced expiratory and inspiratory flow/volume curves [13]. The selection of final values followed criteria outlined previously $[5,13]$.

\section{Statistical analysis}

Data were evaluated in terms of absolute values and changes relative to baseline as measured in the morning. Primary variables taken for evaluation were FEV1 and FIV1. Recovery time was defined as the time interval after saline inhalation that was needed to return to baseline. Mean values and SD or SEM were computed. Repeated measures analysis of variance (ANOVA) was used to compare treatments in terms of absolute values or changes in these values, and post hoc comparisons were performed according to Newman-Keuls. Owing to skewed distributions, recovery times were evaluated by nonparametric Friedman ANOVA and Wilcoxon matched-pairs signed-ranks tests. Statistical significance was assumed at $\mathrm{p}<0.05$.

\section{Results}

Upon inclusion, 11 patients showed an FEV1 of $\leqslant 40 \%$ pred, 13 of $>40$ and $\leqslant 50 \%$ pred, and five of $>50$ and $\leqslant 60 \%$ pred. A total of 23 patients took inhaled $\beta_{2}$-agonists and anticholinergics, nine additional theophylline, and 15 inhaled corticosteroids. The subgroups of patients with steroids and/ or anticholinergics and/or theophylline were to a large extent identical to the group with FEV1 below or equal to the median value $(42.9 \%$ pred; $n=15)$. None of the patients reported having an allergic disease or a respective family history of such a disease. No significant or serious adverse events occurred, except that two patients reported on a mild transient dizziness about $1 \mathrm{~h}$ after the oral medication with montelukast.

\section{Bronchodilation}

Baseline lung function did not significantly differ between study days. At $4 \mathrm{~h}$ changes in FEV1 and FIV1 relative to baseline were significantly different between treatments $(\mathrm{p}<0.0003$; table 2). Specifically, the effects of $\mathrm{S}$ on FEV1

Table 2. - Changes in lung function and recovery time

\begin{tabular}{|c|c|c|c|c|c|c|c|c|c|c|}
\hline & \multicolumn{2}{|c|}{$\begin{array}{c}\text { Change } \\
\text { after } 4 \mathrm{~h}^{\#} \%\end{array}$} & \multicolumn{2}{|c|}{$\begin{array}{c}\text { Change after } \\
\text { additional salbutamol } \%\end{array}$} & \multicolumn{2}{|c|}{$\begin{array}{l}\text { Maximum change } \\
\text { after } 3 \% \text { saline } \%\end{array}$} & \multicolumn{2}{|c|}{$\begin{array}{l}\text { Time needed for } \\
\text { recovery to baseline }{ }^{+} \text {min }\end{array}$} & \multicolumn{2}{|c|}{$\begin{array}{l}\text { Changes } 45 \mathrm{~min} \\
\text { after saline } \%\end{array}$} \\
\hline & FEV1 & FIV1 & FEV1 & FIV1 & FEV1 & FIV1 & FEV1 & FIV1 & FEV1 & FIV1 \\
\hline Placebo & $-1.9 \pm 1.8$ & $-4.7 \pm 1.8$ & $15.1 \pm 2.4$ & $8.3 \pm 2.1$ & $-13.1 \pm 2.4$ & $-26.3 \pm 3.1$ & $15.9 \pm 3.0$ & $21.2 \pm 3.0$ & $0.9 \pm 4.6$ & $-4.3 \pm 4.4$ \\
\hline Salbutamol & $7.3 \pm 2.2$ & $4.5 \pm 1.5$ & $9.0 \pm 2.0$ & $2.5 \pm 1.5$ & $-10.3 \pm 2.7$ & $-25.1 \pm 2.3$ & $16.8 \pm 3.3$ & $20.4 \pm 3.0$ & $1.9 \pm 4.5$ & $0.5 \pm 2.4$ \\
\hline Montelukast & $0.4 \pm 1.6$ & $1.5 \pm 1.6$ & $7.2 \pm 5.9$ & $-1.5 \pm 5.3$ & $-5.8 \pm 2.8$ & $-23.0 \pm 2.7$ & $8.5 \pm 2.4$ & $15.2 \pm 2.7$ & $11.3 \pm 3.5$ & $7.6 \pm 3.0$ \\
\hline
\end{tabular}

Data are presented as mean \pm SEM of $\%$ changes relative to baseline as measured at the beginning of each test. FEV1: forced expiratory volume in one second; FIV1: forced inspiratory volume in one second. \#: $4 \mathrm{~h}$ after oral and $1 \mathrm{~h}$ after inhaled medication; ${ }^{\circ}: 15$ min after the additional $200 \mu \mathrm{g}$ salbutamol that was given before saline inhalation (assessed in $20 / 29$ patients); ${ }^{+}$: time after the end of saline inhalation at which the individual baseline value was reached again. 
were different from both the effects of $\mathrm{P}$ and $\mathrm{M}$ (mean changes after P: $-0.013 \mathrm{~L}, \mathrm{~S}: 0.103 \mathrm{~L}, \mathrm{M}: 0.007 \mathrm{~L}$; $\mathrm{p}<0.01)$. The effects of $\mathrm{M}$ and $\mathrm{S}$ on FIV1 were not different from each other but different from those of P (P: $-0.153 \mathrm{~L}, \mathrm{~S}: 0.166 \mathrm{~L}$, $\mathrm{M}: 0.051 \mathrm{~L} ; \mathrm{p}<0.01)$. The bronchodilator effects of $\mathrm{S}$ on FEV1 were significant $(\mathrm{p}<0.05)$ only in the two subgroups with either high baseline FEV1 or no corticosteroids, whereas the differences regarding FIV1 occurred in all subgroups $(\mathrm{p}<0.05)$.

Patterns identical to those observed for relative changes were obtained when comparing absolute values of FEV1 and FIV1 at $4 \mathrm{~h}(\mathrm{p}<0.01)$. The additional inhalation of salbutamol prior to saline did not alter the result that FEV1 was higher after $\mathrm{S}$ than after $\mathrm{M}$ or $\mathrm{P}(\mathrm{p}<0.05 ; \mathrm{n}=20)$; differences in FIV1, however, were no more statistically significant.

\section{Bronchoprotection}

Figure 1 illustrates the time course of FEV1 and FIV1 after hypertonic saline inhalation. Responses in terms of minimum absolute values of FEV1 were significantly different between treatments $(p=0.0065)$, with $M$ superior to $P(p<0.05)$. Similarly, maximum values after $45 \mathrm{~min}$ of recovery were different $(\mathrm{p}=0.0034)$, with $\mathrm{M}$ superior to both $\mathrm{P}$ and $\mathrm{S}$ $(\mathrm{p}<0.02)$. Saline responses did not differ in terms of FIV1, however, maximum values after recovery were different $(\mathrm{p}=0.0002)$, with $\mathrm{M}$ again being superior to $\mathrm{P}$ and $\mathrm{S}$ $(p<0.01)$. Analogous results $(p<0.05$, each comparison) in
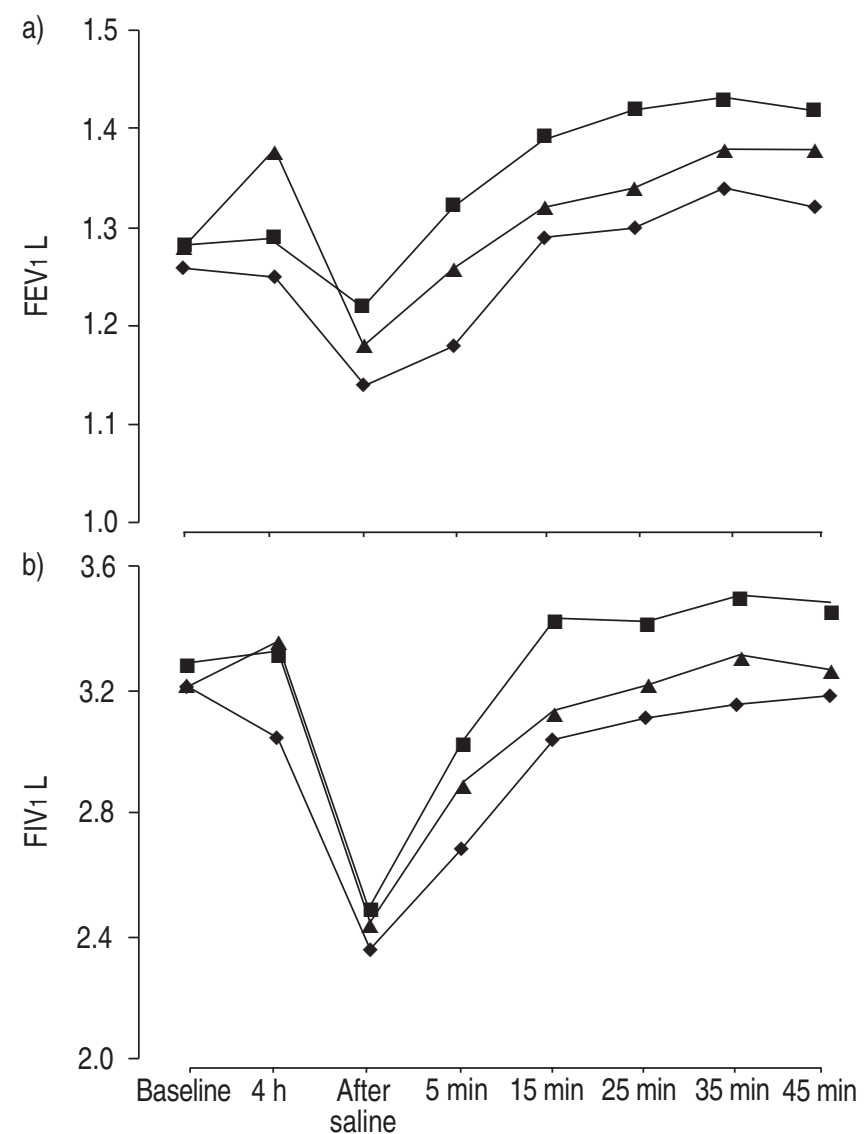

Fig. 1.-Time course of a) forced expiratory volume in one second (FEV1) and b) forced inspiratory volume in one second (FIV1) showing mean values. : treatment with oral placebo plus inhaled placebo; $\boldsymbol{\Delta}$ : oral placebo plus $200 \mu \mathrm{g}$ inhaled salbutamol; $\boldsymbol{\square}: 10 \mathrm{mg}$ montelukast plus inhaled placebo. terms of FEV1 and FIV1 were obtained in the subgroups with low baseline FEV1 and/or inhaled corticosteroids, whereas the effects in the complementary subgroups were not statistically significant.

The maximum fall in FEV1 relative to baseline as measured in the morning was not significantly different between treatments (P: $-0.151 \mathrm{~L}, \mathrm{~S}:-0.115 \mathrm{~L}, \mathrm{M}:-0.070 \mathrm{~L})$, whereas the improvements after recovery were (table 2). Again, $M$ was superior to both P and S (P: 0.115 L, S: 0.125 L, M: $0.206 \mathrm{~L}$; $\mathrm{p}<0.05)$. Analogous results were obtained for FIV1. Salineinduced deteriorations relative to the values measured at $4 \mathrm{~h}$ were additionally evaluated. Effects on FEV1 differed significantly between treatments $(\mathrm{P}:-0.128 \mathrm{~L}, \mathrm{~S}:-0.218 \mathrm{~L}$, M: $-0.078 \mathrm{~L} ; \mathrm{p}<0.05)$, and changes in FIV1 also differed $(\mathrm{p}=0.0058)$, with responses after $\mathrm{P}$ being greatest $(\mathrm{p}<0.03)$.

The recovery time for both FEV1 and FIV1 showed a significant difference between the three treatments $(p<0.008)$. Specifically, times were shortest after $M$ compared with both $\mathrm{S}$ and $\mathrm{P}(\mathrm{p}<0.05)$, whereas values for $\mathrm{P}$ and $\mathrm{S}$ did not differ statistically (table 2). In separate analyses, these effects of $\mathbf{M}$ were significant $(\mathrm{p}<0.05)$ only in the subgroups with low baseline FEV1 and/or corticosteroids.

\section{Discussion}

The data of the present study were obtained using hypertonic saline as a bronchoconstrictor stimulus in patients with COPD. They demonstrate that the antileukotriene receptor antagonist montelukast is capable of exerting beneficial effects, as demonstrated by a reduction in the maximum response to saline, a decrease in the time needed for recovery to baseline, and improved values after recovery particularly in severe COPD. Acute bronchodilation prior to the saline challenge was minor after montelukast, in contrast to salbutamol which, however, did not ameliorate the response to hypertonic saline. It seems noteworthy that the protective effects of montelukast were most obvious in patients with more severe disease as indicated by low baseline FEV1 and/or therapy with inhaled steroids. Neither corticosteroids nor ipratropium or theophylline, as a constant concomitant therapy, were capable of preventing the effects of montelukast on the hypertonic saline response. Although it is currently unknown whether hypertonic saline-induced airway responses reflect a pathophysiologically and clinically relevant feature in these patients, these data suggest it worth considering leukotriene receptor antagonists as a therapeutic option particularly in severe COPD.

Airway responses in terms of FEV1 as well as FIV1 were evaluated. Previous results in patients with severe COPD indicated FIV1 being superior to FEV1 in the assessment of bronchodilation but not bronchoconstriction [5, 13]. The present data are in accordance with that, as bronchodilation by montelukast relative to placebo was apparent only in FIV1; this was even more obvious in the patients with more severe disease. In contrast, the modulation of the bronchoconstrictor response to hypertonic saline by montelukast was better reflected in FEV1.

The rationale for the present study was derived from considering potential mediators of airway obstruction in COPD. The authors previously found that the level of cysteinyl leukotrienes in sputum increased slightly after hypertonic saline inhalation [5]. The significant release of histamine suggested the activation of mast cells, which are also major sources of cysteinyl leukotrienes. The negative finding regarding leukotrienes might have been caused by the fact that their release needed time, whereby the average time of inhalation was only $8.8 \mathrm{~min}$ for hypertonic and $16.5 \mathrm{~min}$ for 
isotonic saline [5]. In addition, airway obstruction, as a potential trigger for leukotriene release, occurred in $50 \%$ of patients even with isotonic saline. In view of the fact that the detection of leukotrienes in sputum supernatants is critical [10], the authors therefore argue that an involvement of leukotrienes could only be proven through an intervention that specifically inhibited their action.

It is suggested by several findings that mast cells play a role in COPD. First, their numbers are increased in the mucosa of proximal [14] or distal [15] airways in chronic bronchitis, in parallel with the deterioration of lung function [16]. Secondly, activation of mast cells in chronic bronchitis is suggested by increased levels of histamine in sputum [17]. Thirdly, patients with COPD experience bronchoconstriction after inhalation of AMP [18], the action of which is thought to be mediated by mast cells [19]; accordingly, the response could be attenuated by an antihistamine [18].

It seems noteworthy that the findings of the current study of an accelerated recovery after montelukast is consistent with data obtained by mannitol as a bronchoconstrictor in asthma [20]. These data showed no effect on the maximum fall in FEV1. Inhalation of mannitol has been suggested to mimic the action of hypertonic saline, at least partially, by altering airway surface osmolarity [21] and activating epithelial cells, sensory nerves and mast cells. With higher concentrations of saline less volume of aerosol is needed to elicit the response, thus the rate of change of osmolarity is thought to be the major causative factor [1]. In vitro studies in human mast cells have demonstrated rapid-onset histamine release caused by hypertonic stimuli [22]. Accordingly, the response to hypertonic saline inhalation in asthma could be attenuated by pretreatment with histamine antagonists [7, 8], a cyclooxygenase inhibitor [8], or atropine and ipratropium [9]. Corresponding data in severe COPD would be of interest not only from a pathophysiological point of view, but could also improve the safety of sputum induction and even help in the patients' treatment.

The rapid onset of airway obstruction and its association with cough suggest neural pathways are involved. In fact, the amount of substance $\mathrm{P}$ in sputum has been found elevated after hypertonic saline inhalation [23]. Interestingly, montelukast can almost block the bronchoconstrictor effect of sulphur dioxide in asthma [24]; this acute response is believed to be largely mediated through neural pathways and possibly includes mast cells [25]. A link between leukotrienes, histamine and neural pathways is also suggested by osmotic analogues of the hypertonic saline challenge [26] or the capability of neuropeptides to elicit histamine release [27]. Thus, in addition to antileukotrienes, antihistamines, nedocromil sodium and antineuropeptides are candidates for preventing the saline response in severe COPD.

To date it is unknown whether the effects elicited by hypertonic saline correspond to clinical outcomes in COPD. Ambient air conditions might be relevant in this respect, as patients with severe COPD often report to suffer in cold, humid and/or foggy weather. Furthermore, the fact that hypertonic saline causes a variety of symptoms even in normal subjects, leads to the speculation that it mimics some functional effects occurring during exacerbations in COPD. Leukocytes from patients with COPD are capable of releasing significant amounts of leukotrine $\mathrm{C}_{4}$ upon stimulation [28] and cysteinyl leukotrienes are produced in response to viral infections [29], as one potential factor in exacerbations. Given that, the airway response to hypertonic saline could be an acute model of the functional although not immunological processes that are acting during exacerbations in COPD. The common link could be airway oedema and plasma extravasation, involving a mode of airway responsiveness and airway protection in severe COPD, which is different from asthma.
This is also suggested by results from the current study in the subgroup with more severe COPD. Interestingly, preliminary data in patients with COPD indicated a reduction in the number and duration of hospitalisations by montelukast, and this was not based on bronchodilation [30].

In accordance with a previous study [5], inhalation of $200 \mu \mathrm{g}$ salbutamol 15 min before hypertonic saline inhalation did not prevent the airway response. Furthermore, responses did not differ between pretreatments with placebo and salbutamol. This seems remarkable in view of the ability of salbutamol to attenuate or prevent bronchoconstrictor responses to a wide variety of stimuli. Furthermore, the result on the protective action of montelukast did not appear to be biased by changes in values prior to provocation. By choosing the morning values as a reference, the authors tried to ensure comparability between measurements and to circumvent the problem that with low FEV1 shifts in baseline can lead to artificial results. The current study was even designed to avoid (trivial) effects of bronchodilation as far as possible. The additional inhalation of salbutamol $15 \mathrm{~min}$ before hypertonic saline inhalation also acted to reduce differences in bronchodilator state prior to challenges. Its effect was not measured in all tests, as the authors considered it secondary and some patients complained of exhaustion from the repeated lung function testing. The additional salbutamol caused an upward shift in FEV1 but did not destroy the differences between medications. Also, taking this value as reference for bronchoconstriction did not abolish the differences. Based on these arguments, it is unlikely that differences in bronchodilation prior to challenges explain the findings. Time courses were clearly separated between medications, as evident from the absolute values of FEV1 (fig. 1).

Lung function values after recovery from saline responses were similar to baseline values after treatment with placebo or salbutamol. In contrast, montelukast led to a significant improvement 45 min later, which could not be attributed to bronchodilation prior to the challenge (fig. 1). It is unlikely that the additional salbutamol caused this effect because the improved recovery did not occur after treatment with salbutamol alone. Thus, either the bronchodilator action of salbutamol has been amplified, or the response to saline inhalation has been improved by montelukast. There is no substantial evidence that montelukast leads to an exaggerated response to $\beta_{2}$-agonists. A natural explanation would be that the saline challenge caused release of both bronchoconstrictor and bronchodilator mediators and that constriction was partially blocked by montelukast, whereas the dilation was not. The present data do not allow this hypothesis to be tested. However, it seems a challenging perspective to elicit significant bronchodilation through a bronchoconstrictor stimulus plus a bronchoprotector that is itself a weak bronchodilator. Whether this observation has clinical implications remains to be established.

In summary, data from the current study indicate that the cysteinyl leukotriene receptor antagonist montelukast has beneficial effects in the model of hypertonic saline-induced airway response, especially in patients with severe chronic obstructive pulmonary disease. The effects were not directly related to bronchodilation and were particularly evident in the recovery from the bronchoconstrictor response. These findings promote the belief that cysteinyl leukotriene antagonism might have a therapeutic potential in chronic obstructive pulmonary disease.

\section{References}

1. Schoeffel RE, Anderson SD, Altounyan RE. Bronchial hyperreactivity in response to inhalation of ultrasonic 
nebulised solutions of distilled water and saline. $\mathrm{Br}$ Med $J$ 1981; 283: 1285-1287.

2. Kips JC, Peleman RA, Pauwels RA. Methods of examining induced sputum: do differences matter? Eur Respir J 1998; 11: $529-533$

3. Richter K, Holz O, Jörres RA, Mücke M, Magnussen H. Sequentially induced sputum in patients with asthma or chronic obstructive pulmonary disease. Eur Respir J 1999; 14: 697-701

4. Rytilä $\mathrm{PH}$, Lindqvist $\mathrm{AE}$, Laitinen LA. Safety of sputum induction in chronic obstructive pulmonary disease. Eur Respir J 2000; 15: 1116-1119.

5. Taube C, Holz O, Mücke M, Jörres RA, Magnussen H. Airway response to inhaled hypertonic saline in patients with moderate to severe COPD. Am J Respir Crit Care Med 2001; 164: 1810-1815.

6. Holz O, Kips J, Magnussen $\mathrm{H}$. Update on sputum methodology. Eur Respir J 2000; 16: 355-359.

7. Rodwell LT, Anderson SD, Seale JP. Inhaled clemastine inhibits airway narrowing caused by aerosols of non-isotonic saline. Eur Respir J 1991; 4: 1126-1134.

8. Finnerty JP, Wilmont C, Holgate ST. Inhibition of hypertonic saline-induced bronchoconstriction by terfenadine and flurbiprofen: evidence for the predominant role of histamine. Am Rev Respir Dis 1989; 140: 593-597.

9. Makker HK, Holgate ST. The contribution of neurogenic reflexes to hypertonic saline-induced bronchoconstriction in asthma. J Allergy Clin Immunol 1993; 92: 82-88.

10. Kelly MM, Keating V, Leigh R, et al. Analysis of fluid phase mediators. Eur Respir J 2002; 20: 24-39.

11. American Thoracic Society. Standards for the diagnosis and care of patients with chronic obstructive pulmonary disease. Am J Respir Crit Care Med 1995; 152: 77-121.

12. Holz O, Jörres RA, Koschyk S, Speckin P, Welker L, Magnussen $\mathrm{H}$. Changes in sputum composition during sputum induction in healthy and asthmatic subjects. Clin Exp Allergy 1998; 28: 284-292.

13. Taube C, Lehnigk B, Paasch K, Kirsten DK, Jörres RA, Magnussen H. Factor analysis of changes in dyspnea and lung function parameters after bronchodilation in chronic obstructive pulmonary disease. Am J Respir Crit Care Med 2000; 162: 216-220.

14. Pesci A, Rossi GA, Bertorelli G, Aufiero A, Zanon P, Olivieri D. Mast cells in the airway lumen and bronchial mucosa of patients with chronic bronchitis. Am J Respir Crit Care Med 1994; 149: 1311-1316.

15. Lamb D, Lumsden A. Intra-epithelial mast cells in human airway epithelium: evidence for smoking-induced changes in their frequency. Thorax 1982; 37: 334-342.

16. Grashoff WF, Sont JK, Sterk PJ, et al. Chronic obstructive pulmonary disease: role of bronchiolar mast cells and macrophages. Am J Pathol 1997; 151: 1785-1790.

17. Turnbull LW, Turnbull LS, Crofton J, Kay AB. Variations in chemical mediators of hypersensitivity in the sputum of chronic bronchitis: correlation with peak expiratory flow. Lancet 1978; 2: 184-186.

18. Rutgers SR, Koëter GH, van der Mark TW, Postma DS Protective effect of oral terfenadine and not inhaled ipratropium on adenosine $5^{\prime}$-monophosphate-induced bronchoconstriction in patients with COPD. Clin Exp Allergy 1999; 29: 1287-1292.

19. Polosa $\mathrm{R}, \mathrm{Ng} \mathrm{WH}$, Crimi $\mathrm{N}$, et al. Release of mast-cellderived mediators after endobronchial adenosine challenge in asthma. Am J Respir Crit Care Med 1995; 151: 624-629.

20. Brannan JD, Anderson SD, Gomes K, King GG, Chan HK, Seale JP. Fexofenadine decreases sensitivity to and montelukast improves recovery from inhaled mannitol. $A m$ J Respir Crit Care Med 2001; 163: 1420-1425.

21. Brannan JD, Anderson SD, Freed R, Leuppi JD, Koskela H, Chan HK. Nedocromil sodium inhibits responsiveness to inhaled mannitol in asthmatic subjects. Am J Respir Crit Care Med 2000; 161: 2096-2099.

22. Eggleston PA, Kagey-Sobotka A, Schleimer RP, Lichtenstein LM. Interaction between hyperosmolar and IgE-mediated histamine release from basophils and mast cells. Am Rev Respir Dis 1984; 130: 86-91.

23. Tomaki M, Ichinose M, Miura M, et al. Elevated substance $\mathrm{P}$ content in induced sputum from patients with asthma and patients with chronic bronchitis. Am J Respir Crit Care Med 1995; 151: 613-617.

24. Gong H Jr, Linn WS, Terrell SL, Anderson KR, Clark KW Anti-inflammatory and lung function effects of montelukast in asthmatic volunteers exposed to sulfur dioxide. Chest 2001; 119: 402-408.

25. Dixon CM, Fuller RW, Barnes PJ. Effect of nedocromil sodium on sulphur dioxide induced bronchoconstriction. Thorax 1987; 42: 462-465.

26. Yang XX, Powell WS, Hojo M, Martin JG. Hyperpneainduced bronchoconstriction is dependent on tachykinininduced cysteinyl leukotriene synthesis. J Appl Physiol 1997; 82: $538-544$

27. Forsythe P, McGarvey LP, Heaney LG, MacMahon J, Ennis M. Sensory neuropeptides induce histamine release from bronchoalveolar lavage cells in both nonasthmatic coughers and cough variant asthmatics. Clin Exp Allergy 2000; 30: 225-232.

28. Mitsunobu F, Mifune T, Hosaki Y, et al. Enhanced production of leukotrienes by peripheral leukocytes and specific IgE antibodies in patients with chronic obstructive pulmonary disease. J Allergy Clin Immunol 2001; 107: 492-498

29. Volovitz B, Welliver RC, De Castro G, Krystofik DA, Ogra PL. The release of leukotrienes in the respiratory tract during infection with respiratory syncytial virus: role in obstructive airway disease. Pediatr Res 1988; 24: 504-507.

30. Kumar B, Schriever CA, Rubinstein I. Long-term montelukast therapy in patients with severe COPD (abstract). Am J Respir Crit Care Med 2002; 165: 228. 